Please do not remove this page

RMIT

UNIVERSITY

\title{
Seismic resilience of retrofitted reinforced concrete buildings
}

Mahini, S; Hadigheh, Seyed Ali; Setunge, Sujeeva

https://researchrepository.rmit.edu.au/esploro/outputs/9921862705301341/filesAndLinks?institution=61RMIT_INST\&index=null

Mahini, S., Hadigheh, S. A., \& Setunge, S. (2015). Seismic resilience of retrofitted reinforced concrete buildings. Proceedings of the Second International Conference on Performance-Based and Life-Cycle Structural Engineering (PLSE 2015), 222-230.

https://researchrepository.rmit.edu.au/discovery/fulldisplay/alma9921862705301341/61RMIT_INST:Resea rchRepository

Document Version: Published Version

Repository homepage: https://researchrepository.rmit.edu.au Copyright (c) 2015 School of Civil Engineering, The University of Queensland and Research Institute for Sustainable Urban Development, The Hong Kong Polytechnic University.

Downloaded On 2023/04/27 01:19:10 +1000 
Thank you for downloading this document from the RMIT Research Repository.

The RMIT Research Repository is an open access database showcasing the research outputs of RMIT University researchers.

RMIT Research Repository: http://researchbank.rmit.edu.aul

\section{Citation:}

Mahini, S, Hadigheh, S and Setunge, S 2015, 'Seismic resilience of retrofitted reinforced concrete buildings', in D. Fernando, J.-G. Teng and J. L. Torero (ed.) Proceedings of the Second International Conference on Performance-based and Life-cycle Structural Engineering (PLSE 2015), Brisbane, Australia, 9-11 December 2015, pp. 222-230.

\section{See this record in the RMIT Research Repository at:}

https://researchbank.rmit.edu.au/view/rmit:35140

Version: Submitted Manuscript

\section{Copyright Statement:}

(C) 2015 School of Civil Engineering, The University of Queensland and Research Institute for Sustainable Urban Development, The Hong Kong Polytechnic University.

Link to Published Version: 


\title{
SEISMIC RESILIENCE OF RETROFITTED REINFORCED CONCRETE BUILDINGS
}

\author{
S.S. Mahini ${ }^{1 *}$, S.A. Hadigheh ${ }^{2}$ and S. Setunge ${ }^{3}$ \\ 1* Discipline of Civil and Environmental Engineering, School of Environmental \& Rural Science, University of \\ New England, NSW, Australia Email: smahini@une.edu.au (corresponding author) \\ ${ }^{2,3}$ School of Civil, Environmental and Chemical Engineering, RMIT University, VIC, Australia
}

\begin{abstract}
The fundamentals of the seismic resilience and evaluation method are presented. The evaluation is based on a non-dimensional analytical function for loss variation and a linear recovery function for a community in an average state of preparedness within a specified 'recovery period'. The loss function is a normalized function where the drop of functionality right after the extreme event. The formulated framework, applied for a complex system of six hospitals (considering direct and indirect losses), is employed for low and medium-rise retrofitted reinforced concrete buildings in which the seismic performance has been evaluated by the displacement-based design method. Although this type of design prevents loss of people life it cannot maintain functionality or limit damages. A newly developed Resilience-Based Earthquake Design is promising to address these demands. This research shows that the FRP retrofit is more effective than steel bracing in terms of improving performance and ductility in low-rise RC buildings and the measuring seismic resilience shows an enhanced value as opposed to the un-retrofitted structure.
\end{abstract}

Keywords: Performance-based design, resilience, seismic, buildings, assessment.

\section{INTRODUCTION}

The main objective of Resilience-Based Design (RBD) is to make communities 'resilient'. It aims to develop actions and technologies that allow structure and/or community to recover its function as promptly as possible whenever a disaster occurs (Cimellaro, 2013). The MCEER terminology defines seismic 'Resilience' as a decision variable (DV) that compares the seismic performance recovery with a given loss required in order to maintain the functionality of the system with minimal disruption. The seismic resilience framework can compare losses and different pre- and post- event measures in order to verify if strategies and actions can reduce or eliminate disruptions during seismic events (Cimellaro, 2008). In this regard, Chang et al. (2004) proposed a series of quantitative measures of resilience and applied them to a case study of an actual community (seismic mitigation of a water system). Biondini et al. (2015) developed a probabilistic approach to the lifetime assessment of seismic resilience of deteriorating concrete structures. Cimellaro et al. (2010) presented a quantitative evaluation of the concepts of disaster resilience and a unified terminology for a common reference framework for the evaluation of health care facilities subjected to earthquakes.

To date, earthquake is considered as part of the general loading requirements applicable to all regions of Australia practically Melbourne and Sydney (Standards Australia 2007 and Wilson et al. 2008). In conventional seismic assessment of structures, the trade-off strength demand is compared with the ductility (displacement) demand on the structure (Lumantarna, et al., 2010). In recent years, performance-based design (PBD) method is implemented in many of the seismic design codes. In this method, performance objective can be the target displacement as the response parameter of a substitute single- degree-of-freedom (SDOF) system which is so-called displacement-based design method (DBDM). It can be also related to strainbased limit state, and the level of damage (Ghobarah, 2001) on a capacity spectrum curve (Hadigeh et al., 2015). ATC-40 (1996) is recommended Capacity Spectrum Method (CSM) for performance assessment of concrete structures. Although, DBDM prevents loss of life, the damages cannot be limited or functionality cannot be maintained.

A number of studies have focused on the influence of retrofitted joints using fibre-reinforced polymers (FRPs) on the overall behaviour of an RC frame. Zou et al. (2007) investigated a 3-storey frame that was strengthened with FRP around its columns. They observed that this could increase the strength of the columns while marginally increasing their stiffness. Reducing stiffness is, however, more desirable for the overall stability of a 
frame, as stiffer columns are more vulnerable to higher seismic forces. Niroomandi et al. (2010) and many recently Hadigeh et al. (2015) studied the seismic performance of RC ordinary moment resisting frames (OMRFs) retrofitted by FRPs or steel braces using DBDM. Hadigeh et al. (2015) showed that while using Xbraces will decrease the ductility of the frames, FRP retrofitting increases the behaviour factor and maintain the ductility within a reasonable margin.

In this paper a formulated framework for a hospital complex system is employed in order to assess the seismic resilience of low-to-medium-rise RC Buildings retrofitted with steel braces and FRP composites (Mahini, 2015, Mahini and Ronagh, 2010, 2011) previously evaluated by DBDM (Niroomandi et al., 2010 and Hadigeh et al., 2015).

\section{PBD OF THE SELECTED RETROFITTED FRAMES}

An eight storey four bay Ordinary Moment Resisting Frame (OMRF) was selected frame. The frame was designed according to the Australian Concrete Code AS3600 (2001) as an OMRF. A 1/2.2 scale model of the frame (see Figure 2a) was then formed by the application of the similitude requirements of the Buckingham's theorem (Mahini, 2005). Based on the scale factors, the scale down frame was loaded, analysed and designed according to AS3600. Four N12 ( $\phi 12 \mathrm{~mm})$ rebars were used for both the column vertical reinforcement and the beam longitudinal reinforcement. R6.5 bars $(\phi 6.5 \mathrm{~mm})$ were used for stirrups at a spacing of $150 \mathrm{~mm}$ in both beam and column. A $30 \mathrm{~mm}$ concrete cover was considered for the beam and column reinforcements which is about half of the corresponding covers in prototype. The tensile properties of various deformed N12 reinforcing steel bars and plain R6.5 ( $\phi 6.5 \mathrm{~mm})$ stirrups and ties are obtained by testing them under monotonic loading in a Universal Testing Machine (UTM) using a mechanical extensometer of 20mm gage length. The average yield strengths of deformed N12 reinforcing steel bars and plain R6.5mm stirrups and ties, were $507 \mathrm{MPa}$ and 382 $\mathrm{MPa}$ respectively and the modulus of elasticity of both reinforcements was 200GPa. Four N12 rebars were used for both the column vertical reinforcement and the beam longitudinal reinforcement. R6.5 bars were used for stirrups with a spacing of $150 \mathrm{~mm}$ in both column and beam.

To study the seismic behaviour of low-rise frames, a 2-storey and a 4-storey frame, retrofitted by FRP materials and by steel braces, two OMRFs were investigated (Figure 2c). The column and beam dimensions are presented in Table 1 . The vertical gravity loads were calculated as D.L. $=21.6 \mathrm{kN} / \mathrm{m}$ and L.L. $=13.7 \mathrm{kN} / \mathrm{m}$, and equivalent static earthquake lateral loads on the frames were derived by using the design response spectrum of Standard No. 2800 (2005).

In the case of steel brace retrofitting, braces were placed in the middle bay of the frames. For the FRP retrofitting technique, all of the joints (except the joints of the last floor) were retrofitted on their web by FRP sheets with overall $2 \mathrm{~mm}$ thickness and a length of 350mm (Figure 2b). Further details of the FRP-retrofitting design can be found in Mahini (2005). For simplicity, the FRP retrofitting scheme is designed based on the critical joint at the first floor and is then kept identical for other levels in order to guarantee that the plastic hinge relocations are formed in the upper levels and prove the practicality of the proposed retrofitting system in a realworld application.

A nonlinear static procedure (NSP) represents the response of a structure undergoing dynamic loads. A pushover analysis, as a nonlinear static procedure, is employed as an alternative for static and nonlinear dynamic analysis because of its accuracy and simplicity. To study the influence of the retrofitting technique, a nonlinear pushover analysis was performed for both the original and the retrofitted frames. The moment-rotation relationship of the joints (obtained from ABAQUS) was then incorporated into the FE models of the frames and pushover analyses were carried out. The lateral load distribution is proportional to the product of the storey mass and the first mode shape of the structure. The mass source of frame is assumed to be the dead load plus $20 \%$ of the live load, according to Standard No. 2800 (2005).

To evaluate the seismic load, it was assumed that the frames are located in a zone with a high seismic hazard $(\mathrm{DBA}=0.35 \mathrm{~g})$. The seismic reduction factor was initially assumed to be $R=4$ and $75 \%$ of the lateral load $(0.75$ $\mathrm{V})$ was applied to the design of each RC frame. However after adding the X-steel brace to the RC frames $100 \%$ of the lateral load was applied $(V)$. Therefore, the steel braces were designed to withstand a $25 \%$ share of the lateral load. In case of FRP retrofitting, frames were designed with $75 \% \mathrm{~V}$ and retrofitted with FRP sheets. Details of the bracing system are presented in Hadigeh et al. (2015). The compressive strength of the concrete and the yield stress of the steel reinforcements were assumed to be $40 \mathrm{~N} / \mathrm{mm}^{2}$ and $340 \mathrm{~N} / \mathrm{mm}^{2}$, respectively. For all sections, the minimum and maximum values of the steel reinforcements were checked against the ABA concrete code (2005). 
According to FEMA 356 (2000), the state of building damage under earthquake excitation defines the performance level of a building by considering the vertical and horizontal lateral-force-resisting elements. These performance levels consist of three main objectives; immediate occupancy (IO), life safety (LS) and collapse prevention (CP). Life safety is defined as the post-earthquake state that includes damage to the elements but retains a margin against the onset of a partial or total collapse in the structure (FEMA 2000). For instance, Figure 3 represents the plastic hinge distributions at the specific performance levels of the original and retrofitted 4- and 8-storey structures.

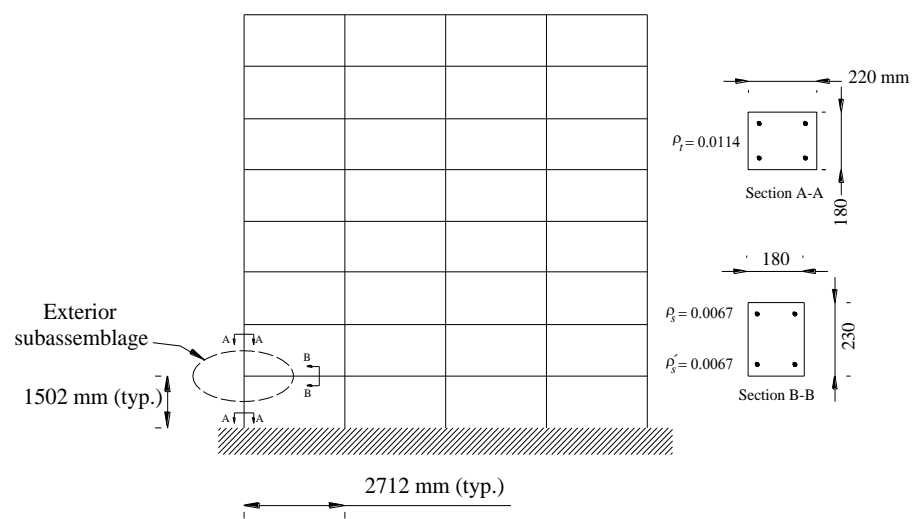

(a)

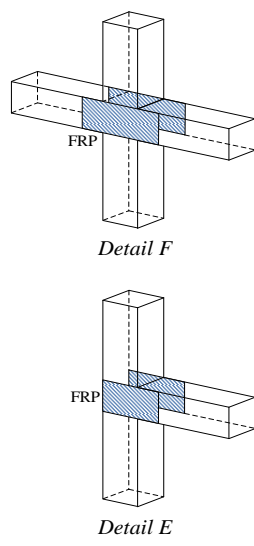

(b)

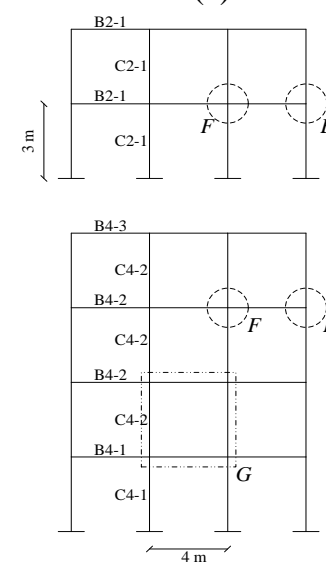

(c)

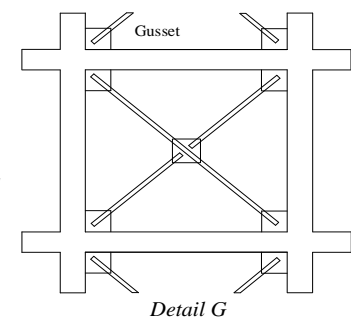

(d)

Figure 2. Studied frames, (a) geometry of eight-storey frames (b) FRP strengthening details, (c) geometry of two and four-storey frames, and (d) steel bracing system (Hadigeh et al., 2015).

Table 1 Column and beam dimensions of 2- and 4-storey frames

\begin{tabular}{|c|c|c|c|}
\hline Section & $\begin{array}{c}\text { Height } \\
(\mathrm{mm})\end{array}$ & $\begin{array}{c}\text { Width } \\
(\mathrm{mm})\end{array}$ & $\begin{array}{c}\text { Longitudinal } \\
\text { Reinforcement }(\%)\end{array}$ \\
\hline C2-1, 2 & 300 & 300 & 2.053 \\
\hline B2-1, 2 & 400 & 300 & $\begin{array}{c}1.166(\text { Top) } \\
0.528(\text { Bottom) }\end{array}$ \\
\hline C4-1 & 450 & 450 & 1.007 \\
\hline C4-2, 3,4 & 350 & 350 & 1.312 \\
\hline B4-1 & 450 & 450 & $\begin{array}{c}0.638 \text { (Top) } \\
0.503 \text { (Bottom) }\end{array}$ \\
\hline B4-2, 3 & 350 & 350 & $\begin{array}{c}1.396(\text { Top) } \\
0.684 \text { (Bottom) }\end{array}$ \\
\hline B4-4 & 300 & 300 & $\begin{array}{c}1.286(\text { Top) } \\
0.986 \text { (Bottom) }\end{array}$ \\
\hline
\end{tabular}


In the 8-storey frames, no plastic hinges are formed on the $6^{\text {th }}$ floor after retrofitting. In the plain eight-storey frame, approximately 74 per cent of plastic hinging occurs on the beams, whereas the FRP retrofitted frames exhibit a 5 per cent improvement in beam hinging. This trend was observed in previous research (Niroomandi et al. 2010) for plain frames but not for FRP retrofitted frames (in which plastic hinging in the beams was similar). This can be explained from the difference between the additional moment-rotation stiffness of the retrofitted joints; in (Niroomandi et al. 2010), only the peak strengths were captured and implemented in the pushover analysis. The steel braces are not promising in this regard, as only 62 to 66 per cent of hinges formed on beams. Although no beam hinging occurred in the low-rise building frames after FRP retrofitting, the plastic hinging improved in the 4-storey building, which was reclassified from Collapse (C) to the acceptance criteria of Immediate Occupancy (IO). This trend was also observed for a 2-story frame. However, the plastic hinge numbers increased after FRP retrofitting. Again, the steel braced systems exhibit lower plastic hinge formation, and a lower ductility demand is therefore expected for this system.

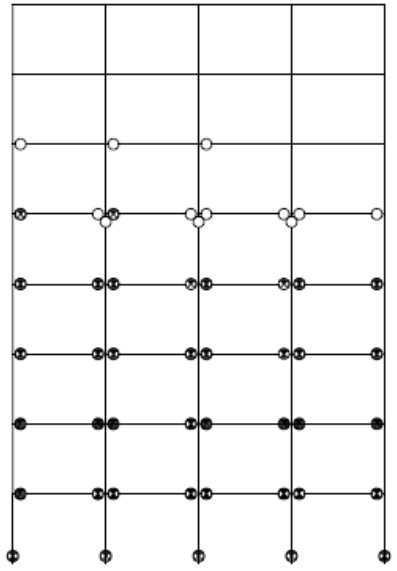

(a)

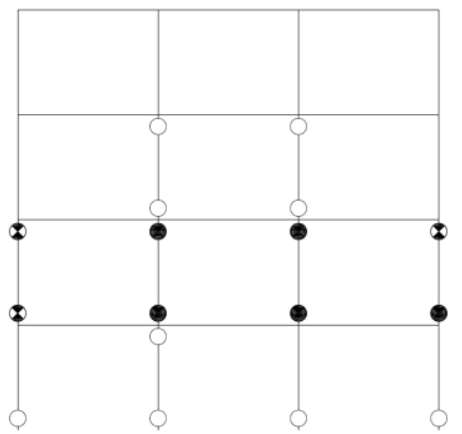

(c)

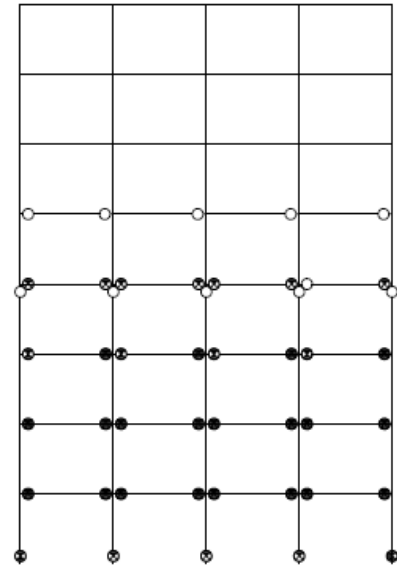

(b)

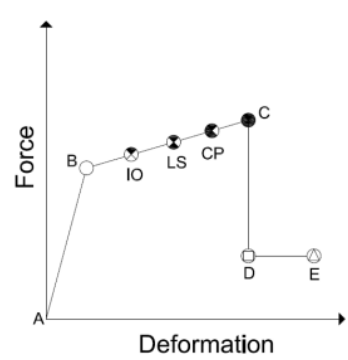

Deformation

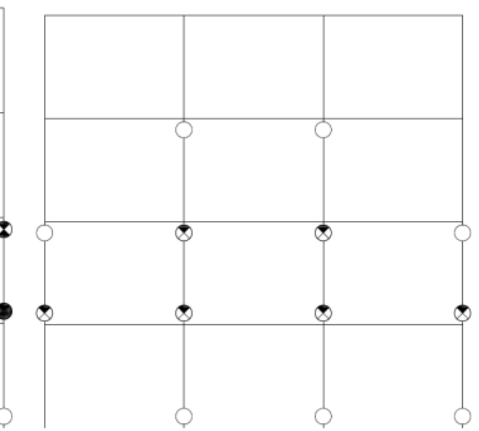

(d)

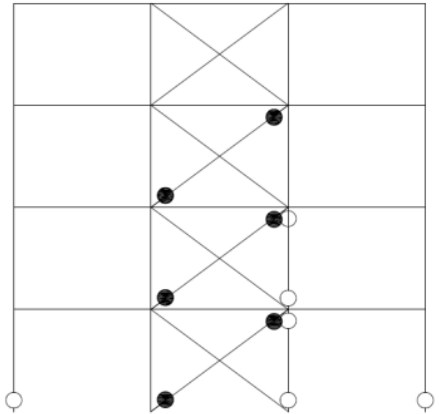

(e)

Fig. 3. Plastic hinge formation for (a) original 8-storey, (b) FRP retrofitted 8-storey, (c) original 4-storey, (d) FRP retrofitted 4-storey and (e) steel-braced 4-storey frames.

Therefore, the retrofitted frames meet the performance objectives of life safety. According to these results, this retrofitting technique can improve the behaviour of the frame under earthquake motions to the desired level. It should be noted that response spectrum of Standard 2800 is much higher than the response spectrum of the Australian Standard AS1170.4 (1993) because earthquake hazards in Australia are lower than in Iran. As the original frame was designed according to the Australian seismic code the shortfall of the frame is explained by the differences between the Iranian and the Australian response spectra. However, the FRP retrofitting of the joints upgraded the frame to satisfy the LS performance level of Standard 2800.

Table 2 presents the performance points of the frames. According to this table, the FRP-retrofitting of the 4storey frame failed to upgrade the frame to satisfy the life-safety performance demand of the selected Standard 2800 earthquake, indicating insufficient thickness for the FRP laminates. However the steel bracing of the frames considerably enhanced the performance to meet the required LS demands by substantially increasing capacities of the frames at the expense of highly reduced ductility. 
Table 2. Performance points of the original and retrofitted frames

\begin{tabular}{|c|c|c|c|}
\hline \multirow{2}{*}{ Type of frame } & \multicolumn{3}{|c|}{ Performance point $\left(S_{d}, S_{a}\right)$} \\
\cline { 2 - 4 } & 2-storey & 4-storey & 8-storey \\
\hline Plain & $(4.00,0.36 \mathrm{~g})$ & $(2.66,0.27 \mathrm{~g})$ & N.A. \\
\hline $\begin{array}{c}\text { Retrofitted with } \\
\text { FRP laminates }\end{array}$ & $(3.79,0.38 \mathrm{~g})$ & N.A. & $(12.27,0.126 \mathrm{~g})$ \\
\hline $\begin{array}{c}\text { Retrofitted with X- } \\
\text { braced steel }\end{array}$ & $(1.00,0.70 \mathrm{~g})$ & $(0.92,0.66 \mathrm{~g})$ & --- \\
\hline
\end{tabular}

\section{DEFINITION OF RESILIENCE}

Resilience is the capability of the system to sustain the effects $\Delta \mathrm{Q}$ of the extreme event at time $t_{\mathrm{oE}}$ and to recover efficiently a target level of functionality $\mathrm{Q}(\mathrm{t})$ at time $\mathrm{t}_{\mathrm{OE}}$ plus $\mathrm{T}_{\mathrm{LC}}$. For a single event, it can be defined by the following equation.

$$
R=\int_{t_{O E}}^{t_{O E}+T_{L C}} Q(t) / T_{L C} d t
$$

where

$$
\left.Q(t)=\left[1-L\left(I, T_{R E}\right)\right]\left[H\left(t-t_{O E}\right)-H\left(t_{O E}+T_{R E}\right)\right)\right]\left\{f_{\operatorname{Rec}}\left(t, t_{O E}, T_{R E}\right)\right\}
$$

where $t_{O E}$ is the time of occurrence of event, $T_{L C}$ is the control time of the system $E, L\left(I, T_{R E}\right)$ is the loss function; $H()$ is the Heaviside step function, $f_{\mathrm{Rec}}\left(t, t_{O E}, T_{R E}\right)$ is the recovery function and $\mathrm{T}_{\mathrm{RE}}$ is the recovery time from event $E$ necessary to go back to pre-disaster condition evaluated starting from $\mathrm{t}_{\mathrm{OE}}$.

The Resilience can be illustrated graphically as the normalized shaded area underneath the functionality function of a system, Q (t). Q (t) is a non-stationary stochastic process and each ensemble is a piecewise continuous function as the one shown in Figure 1, where the functionality $Q(t)$ is measured as a percentage function of time.

In this figure, $\mathrm{L}$ is the loss, or the drop of functionality, right after the extreme event, and $\mathrm{R}$ is the Robustness which is strength, or the ability of elements, systems and other measures of analysis to withstand a given level of stress or demand without suffering degradation or loss of function. It is therefore the residual functionality right after the extreme event and can be represented by:

Robustness $(\%)=1-\mathrm{L}\left(\mathrm{m}_{\mathrm{L}}, \sigma_{\mathrm{L}}\right)$

where $\mathrm{L}$ is a random variable expressed as a function of the mean $\mathrm{m}_{\mathrm{L}}$ and the standard deviation $6 \mathrm{~L}$.

Normally, three different types of recovery functions which are (i) linear, (ii) exponential and (iii) trigonometric can be selected depending on the system (resources and societal response) and societal preparedness.

The simplest form; linear recovery function, is used herein as there is no information available regarding the preparedness, resources and societal response as follows.

$$
f_{\operatorname{Re} c}(t)=a\left(\frac{t-t_{O E}}{T_{R E}}\right)+b
$$




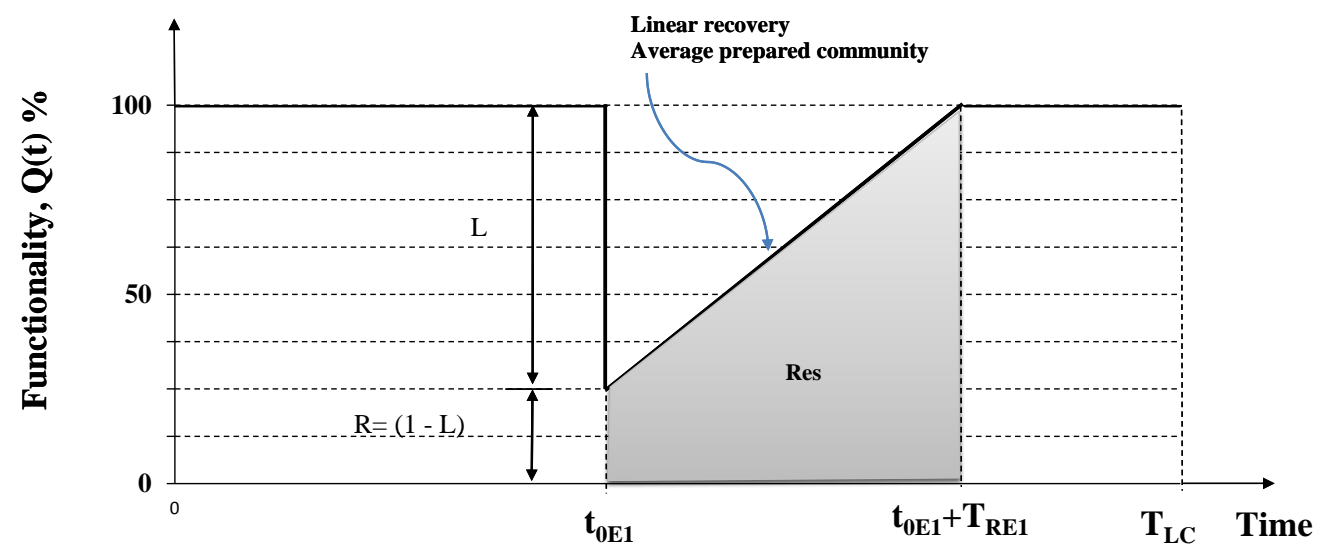

Figure 1. Resilience-Functionality curve: average prepared community

REFERENCE CASE STUDY: Hospital building (Cimerallo et al., 2010)

To illustrate the proposed framework equation (Eq. 1) a complex of six hospitals located in Memphis, Tennessee has been selected (Figure 4). It consists of a regional loss estimation study aimed at the estimation of economic losses of several buildings within a geographical region like a city. Figure 4 shows the locations by Zip codes that were used to define the seismic Hazard and the structural type of the hospitals used to define the structural vulnerability.

Four seismic rehabilitation alternative schemes are considered for each structural type as per FEMA 276: 1) no action; 2) rehabilitation to LS level; 3) rehabilitation to IO level; 4) construction of a new building which are the target performance levels for rehabilitation against an earthquake.

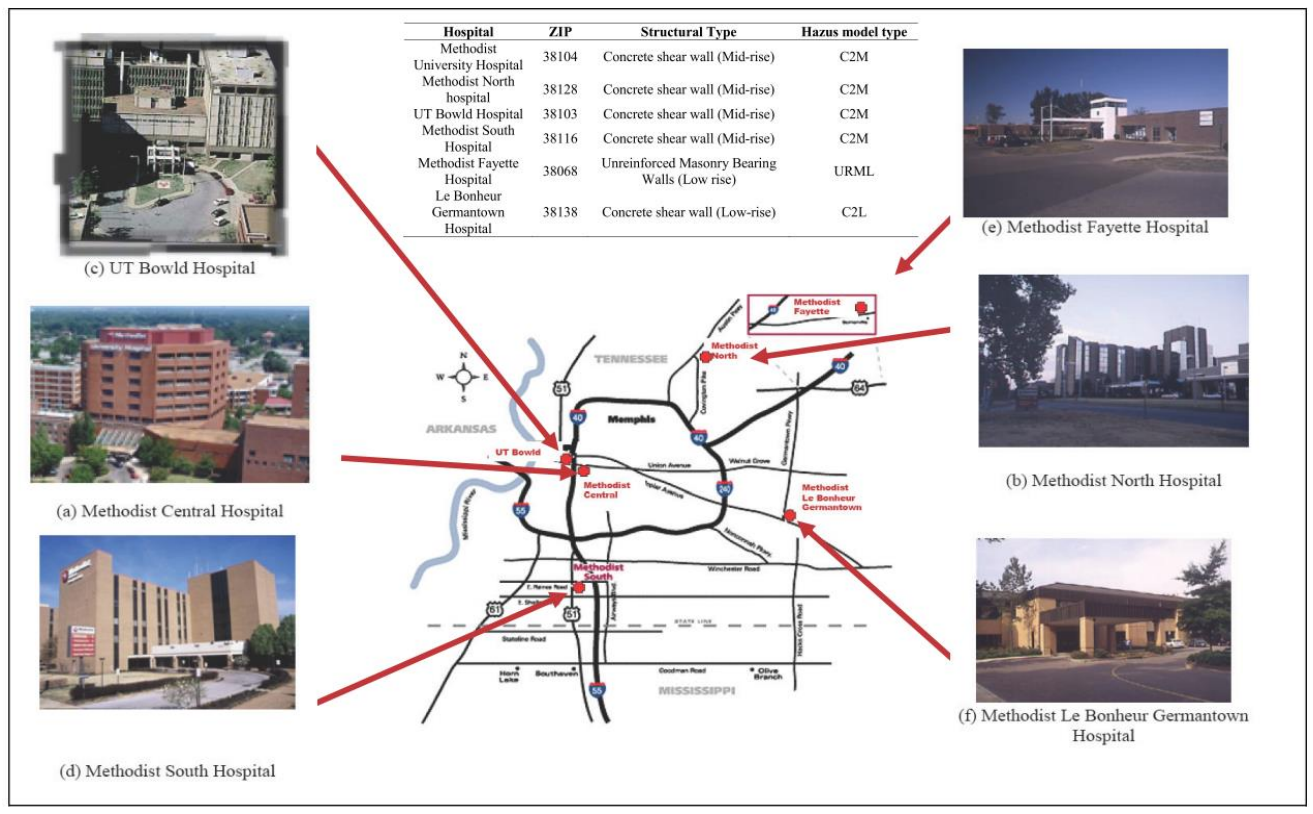

Figure 4. System definition (Cimerallo et al., 2010)

In order to avoid the seismic record the input value was normalized using the four different hazard levels. After normalization the value were determined for different rehabilitation strategies (Figure 5). In order to improve the disaster resilience of the hospital system, four different seismic retrofit schemes were considered for this reference case study: (a) Moment resisting frames (MRF); (b) Buckling restrained braces (UB); (c) Shear walls (SW) and (d) Weakening and Damping (Cimerallo et al., 2010). 
The disaster resilience value is calculated according to Eq. (1). The expected equivalent earthquake losses for each rehabilitation scheme were obtained considering the probability of each level of the earthquake, along with the initial rehabilitation costs, followed by the total expected losses considering an observation period $\mathrm{T}_{\mathrm{LC}}$ of 30 years.

The recovery time and resilience values of this case study are shown in Figure 5. It is shown that the Rebuild option has the largest disaster resilience of $96.5 \%$, when compared with the other three strategies, but it is also the most expensive solution. When No Action is taken, however, the disaster resilience is still reasonably high (81.9\%). Based on Cimellaro (2008), the initial investments and resilience are not linearly related.

When the functionality $\mathrm{Q}(\mathrm{t})$ is very high for it to be improved by a small amount it is required to invest a very large amount compared with the case when the function $Q(t)$ of the system is low. Although this is obvious the procedure presented herein can be used by decision makers.
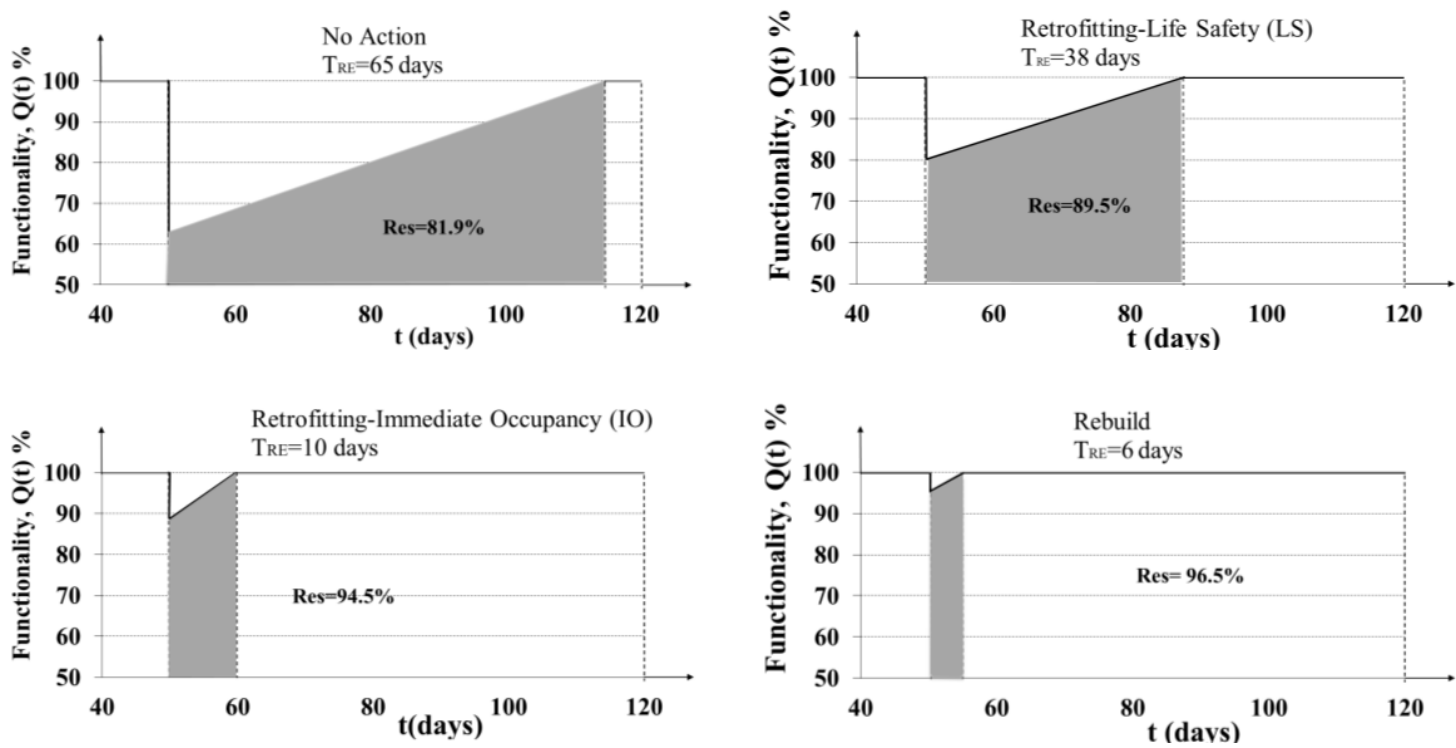

Figure 5. Resilience for different retrofitting strategies, adapted from Cimellaro (2008).

\section{SEISMIC RESILIENCE OF RETROFITTED OMRFs (this study)}

Table 3 shows the values of resilience for the two different retrofit techniques (FRP and X-braces) and for different low-to-medium-rise RC frames (see Figure 2).

This shows that the best improvement in terms of resilience is obtained using a FRP retrofit strategy for 2 and 4 storey frames. However with the 8-storey building both retrofitting strategies led to the same improvement in shifting the building performance to the LS level.

Although in term of resilience the difference seems small, the loss term of ductility (complementary to resilience) clearly shows the advantage of the FRP scheme. This retrofit technique produces a reduction of displacements and maintains the ductility, regardless of the number of stories. The maintenance of ductility is important for RC OMRFs as it is not desirable in the seismic performance of existing frames with OMRFs.

The steel bracing considerably enhanced the performance of the frames to meet the required life-safety demands by substantially increasing strength capacity of the frames at the expense of highly reduced ductility and lower seismic resilience. 
Table 3 Recovery time and resilience of $\mathrm{RC}$ frames for rehabilitation strategies $\left(\mathrm{T}_{\mathrm{LC}}=65\right.$ days).

\begin{tabular}{|c|c|c|c|c|c|c|}
\hline $\begin{array}{l}\text { Rehabilitation } \\
\text { Alternatives }\end{array}$ & $\begin{array}{l}\text { Performance } \\
\text { level }\end{array}$ & $\begin{array}{c}2- \\
\text { storey }\end{array}$ & 4-storey & 8 -storey & $\begin{array}{c}\text { Recovery } \\
\text { Time } \mathrm{T}_{\mathrm{RE}}, \\
\text { [days] }\end{array}$ & $\begin{array}{c}\text { Resilience } \\
\text { Res [\%] }\end{array}$ \\
\hline \multirow{4}{*}{ Plain } & No Action & 0 & O & O & 65 & 81.9 \\
\hline & Life Safety (LS) & NA & NA & NA & - & - \\
\hline & $\begin{array}{l}\text { Immediate } \\
\text { Occupancy (IO) }\end{array}$ & NA & NA & NA & - & - \\
\hline & Rebuild & O & O & - & 6 & 96.5 \\
\hline \multirow{2}{*}{$\begin{array}{l}\text { Retrofitted } \\
\text { with FRP } \\
\text { sheets }\end{array}$} & Life Safety (LS) & - & - & ○ & 38 & 89.5 \\
\hline & $\begin{array}{l}\text { Immediate } \\
\text { Occupancy (IO) }\end{array}$ & $\bullet$ & 0 & - & 10 & 94.5 \\
\hline \multirow{2}{*}{$\begin{array}{c}\text { Retrofitted } \\
\text { with X-braced } \\
\text { steel } \\
\end{array}$} & Life Safety (LS) & - & - & - & 38 & 89.5 \\
\hline & $\begin{array}{l}\text { Immediate } \\
\text { Occupancy (IO) }\end{array}$ & - & - & - & - & - \\
\hline
\end{tabular}

\section{CONCLUSIONS}

Resilience-based design integrates information from these different fields such as earthquake engineering, social science and economics into a unique function leading to results that are unbiased by uninformed intuitions or preconceived notions of risk. This paper aims to provide a quantitative definition of seismic resilience versus the more conventional DBDM method in OMRFs retrofitted with FRPs or X-braced steel techniques. In this rational way an analytical function is used that may fit both technical and organizational issues. A regional complex of six hospitals built in low to medium-rise concrete frames has been used as a reference to illustrate the applicability of the framework and to assess the seismic resilience of the selected retrofitted OMRFS versus the DBDM assessment technique. It is shown that FRP retrofitting improves resilience up to $15 \%$ from $89.5 \%$ to $94.5 \%$.

It is concluded that FRP retrofit is more effective in terms of improving both performance and ductility in lowrise RC buildings as well as an enhanced value of seismic resilience compared to the un-retrofitted structure. However, the assumptions made herein are only representative for the cases presented.

\section{REFERENCES}

ABA (2005), 'Iranian Concrete Code', Iran Management and Planning Organization.

AS1170.4 (1993), 'Structural design Actions Part 4: Earthquake Actions in Australia', Standards Australia, Sydney, Australia.

AS1170.4 (2007), 'Structural design actions Part 4: Earthquake actions in Australia'. Standards Australia.

AS3600 (2001), 'Concrete Structures'. Standards Australia, Homebush Bay, Australia.

Applied Technology Council (ATC) (1996), 'Seismic Evaluation and Retrofit of Concrete Buildings', Report No. ATC-40, Redwood City, California.

Biondini, F., Camnasio, E. and Titi, A. (2015). 'Seismic resilience of concrete structures under corrosion.' Earthquake Engng Struct. Dyn. Published online in Wiley Online Library (wileyonlinelibrary.com). DOI: 10.1002/eqe.2591.

Chang, S., Shinozuka M. (2004), 'Measuring Improvements in the disaster Resilience of Communities', EER/ Spectra Journal, 20, (3), 739-755.

Cimellaro, G. P. (2008), 'Seismic resilience of a regional system of hospitals'. Multidisciplinary Center for Engineering Research (MCEER) publication.http://mceer.buffalo.edu/publications/resaccom/07-SP05/01Cimellaro.pdf.

Cimellaro, G. P. (2013), 'Resilience-based design (RBD) modelling of civil infrastructure to assess seismic hazards' in 'Handbook of Seismic Risk Analysis and Management of Civil Infrastructure Systems, A volume in Woodhead Publishing Series in Civil and Structural Engineering Edited by: S. Tesfamariam and K. Goda, ISBN: 978-0-85709-268-7. 
Cimerallo, G.P., Reinhorn, A.M., and Bruneau, M. (2010), 'Framework for analytical quantification of disaster resilience.' Engineering Structures 32, 3639-3649.

FEMA (2000), 'Prestandard and commentary for the seismic rehabilitation of buildings.' FEMA 356, Washington, D.C.

Hadigheh, S. A., Mahini, S.S. and Maheri, M.R. (2014), 'Seismic behaviour of FRP-retrofitted reinforced concrete frames' , Journal of Earthquake Engineering, 18, 1171-1197, (ISSN: 1363-2469 print / 1559808X online. DOI: 10.1080/13632469.2014.926301).

Lumantarna, E., Lam, N., Wilson, J. and Griffith, M. (2010), 'Inelastic displacement demand of strengthdegraded structures', Journal of Earthquake Engineering, 14, 487-511.

Niroomandi, A., Maheri, A., Maheri, M. R. and Mahini, S. S. (2010), 'Seismic performance of ordinary RC frames retrofitted at joints by FRP sheets' Engineering Structures, 32(8), 2326-36.

Mahini, S.S. (2005), 'Rehabilitation of Exterior RC Beam-Column Joints using CFRP Sheets', PhD thesis submitted to the Division of Civil Engineering of the University of Queensland, Australia.

Mahini, S. S. and Ronagh, H. R. (2010), 'Strength and ductility of FRP web-bonded RC beams for the assessment of retrofitted beam-column joints', Composite Structures, 92(6), 1325-32.

Mahini, S. S. and Ronagh, H. R. (2011), 'Web-bonded FRPs for relocation of plastic hinges away from the column face in exterior RC joints', Composite Structures, 93, 2460-2472.

Standard No. 2800 (2005), 'Iranian code of practice for seismic resistant design of buildings.' Third edition, Building and Housing Research Centre, Tehran, Iran.

Wilson J., L., Lam, N., T., K, and Pham, L. (2008), 'Development of the New Australian Earthquake Loading Standard', EJSE Special Issue: Earthquake Engineering in the low and moderate seismic regions of Southeast Asia and Australia, 25-31.

Zou, X. K., Teng, J. G., De Lorenzis, L., and Xia, S. H. (2007). "Optimal performance-based design of FRP jackets for seismic retrofit of reinforced concrete frames." Composites Part B: Engineering, 38(5-6), 584597. 